\title{
Toward a better understanding of Ni-based ohmic contacts on SiC
}

\author{
Satoshi Tanimoto ${ }^{1,2, a}$, Masanori Miyabe ${ }^{2, b}$, Takamitsu Shiiyama², \\ Tatsuhiro Suzuki ${ }^{2}$, Hiroshi Yamaguchi ${ }^{3}$, Shinichi Nakashima ${ }^{3}$ \\ and Hajime Okumura ${ }^{3}$
}

${ }^{1} 3$ rd R\&D Center, FUPET, c/o AIST. Central 2-10, 1-1-1, Umezono, Tsukuba 305-8568, Japan

${ }^{2}$ YE0-NRD, Nissan Motor Co., Ltd., 1, Natsushima, Yokosuka 237-8523, Japan

${ }^{3}$ ADPERC, AIST, Central 2, 1-1-1, Umezono, Tsukuba 305-8568, Japan

as-tanimoto@mail.nissan.co.jp

Keywords: Ni-based contact, Ni silicide, Ohmic contact, Schottky contact, Power device, TLM.

\begin{abstract}
There is still little consensus regarding why low contact resistivity is achieved when Ni on n-type $4 \mathrm{H}$ - and $6 \mathrm{H}-\mathrm{SiC}$ is annealed at temperatures above $950^{\circ} \mathrm{C}$. The objective of this paper is to provide an answer to this question. It has been reported that even Ni-based contacts formed in the $\mathrm{n}++$ region exhibited a steep reduction of contact resistivity in an annealing temperature range $>900^{\circ} \mathrm{C}$. This reduction cannot be explained by the carbon vacancy induced donor model (Vc model) proposed by Han and his coworkers [Appl. Phys. Lett., Vol. 79, p. 1816 (2001)]. It was observed that the surface of substrates annealed at $1000^{\circ} \mathrm{C}$ was not covered with $\mathrm{Ni}_{2} \mathrm{Si}$ but with a thin layer of NiSi. Finally, a plausible model is proposed that annealing at higher temperatures results in the formation of a NiSi/SiC system at the substrate interface, causing contact resistivity to be reduced significantly.
\end{abstract}

\section{Introduction}

Ohmic contacts in power devices play an extremely important role in the injection and ejection of high current from and to the power source and electrical load. Ni-based contacts, fabricated by thin $\mathrm{Ni}$ film deposition followed by rapid thermal annealing (RTA) at $950^{\circ} \mathrm{C}-1050^{\circ} \mathrm{C}$, have now become the mainstream contacts to the n-type region on $\mathrm{SiC}$ power devices. However, as reviewed by Roccaforate [1], there is still little consensus regarding why low contact resistivity is achieved when $\mathrm{Ni}$ is annealed at temperatures above $950^{\circ} \mathrm{C}$. The objective of this paper is to present some experimental results that provide an answer to this question.

\section{Experimental}

Linear transmission line model (TLM) contacts $100 \times 200$ $\mu \mathrm{m}^{2}$ in area and Schottky barrier diodes (SBDs) $200 \mu \mathrm{m}$ in diameter with Ni-based electrodes were fabricated together on $8^{\circ}$ off-cut $(0001)_{\mathrm{Si}}$ face $\mathrm{n}+4 \mathrm{H}-\mathrm{SiC}$ substrates with an epitaxially grown $10-\mu$ m-thick n-layer (Fig. 1). The electrodes were prepared by RTA of 50 -nm-thick Ni at temperatures ranging from $600^{\circ} \mathrm{C}$ to $1000^{\circ} \mathrm{C}$. The RTA time was $30 \mathrm{~min}$ at $600^{\circ} \mathrm{C}, 5 \mathrm{~min}$ at $700^{\circ} \mathrm{C}$ and $2 \mathrm{~min}$ at the other higher temperatures. The TLM contacts, having a $\mathrm{Ta} / \mathrm{TaN} / \mathrm{Al}-\mathrm{Si}$ overlayer, were formed in phosphorus ion hot-implanted and activated $\mathrm{n}++$ regions $\left(\mathrm{N}_{\mathrm{D}}=2.5 \times 10^{20}\right.$ $\mathrm{cm}^{-3}, \mathrm{X}_{\mathrm{j}}=250 \mathrm{~nm}$ ), which were electrically isolated from the substrate and the surrounding area by p-well $(\mathrm{Al}+)$

(a)

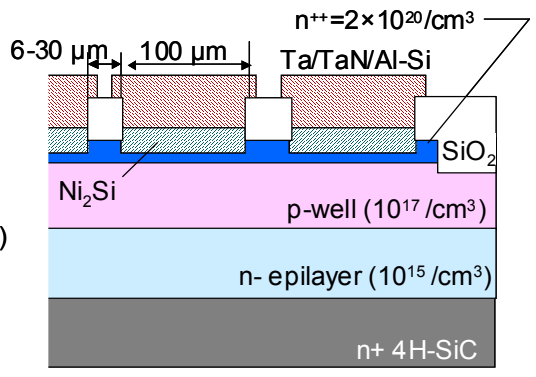

(b)

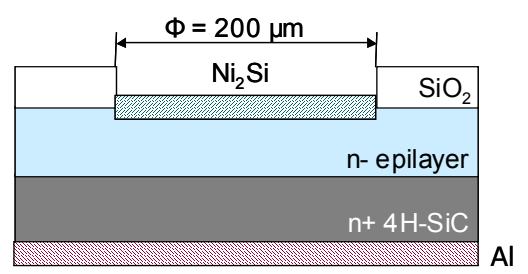

Fig. 1 Cross-sectional structure of sample: (a) TLM contacts and (b) Schottky barrier diode 
implantation and mesa etching. The fabrication process is described in $\S 13.2 .3$ and $\S 13.2 .4$ of Ref. 2 . The Al electrode was deposited at the back side of the SBDs by electron beam (EB) evaporation after removal of the back thermal-oxide preceded by top Ni-silicide formation, which showed superior ohmic contact properties. Blanket Ni-based electrode samples were also formed on epitaxial $4 \mathrm{H}-\mathrm{SiC}$ substrates for physical characterization by X-ray diffraction spectroscopy (XRD) and cross-sectional transmission electron spectroscopy-energy dispersive X-ray spectroscopy (XTEM-EDS). All Ni-based electrodes (or contacts) described here were formed by high-vacuum EB deposition just after removal of the surface thermal oxide immediately followed by RTA under an Ar ambient with a very low dew point. The specific contact resistivity, $\rho_{\mathrm{C}}$, of the TLM contacts was precisely measured with the transfer length method and a four-point probe remote sensing technique. XRD $(\theta-2 \theta)$ analysis revealed that silicidation of $\mathrm{Ni}$ was completed for all the samples and that only the $\mathrm{Ni}_{2} \mathrm{Si}$ phase was detected regardless of the annealing temperature.

\section{Results and Discussion}

The TLM contacts exhibited linear I-V characteristics independent of the RTA temperature, $\mathrm{T}_{\mathrm{A}}$, even for the as-deposited sample. Figure 2 shows the logarithmic average $\rho_{C}$ as a function of $T_{A}$, indicating a steep decline in $\rho_{\mathrm{C}}$ at temperatures over $800^{\circ} \mathrm{C}$. The minimum $\rho_{\mathrm{C}}=1.1 \times 10^{-6} \Omega \mathrm{cm}^{2}$ was attained at $1000^{\circ} \mathrm{C}$. A similar result was previously reported for TLM contacts in an $\mathrm{n}+$ epilayer on p-type $4 \mathrm{H}$-SiC, in which nitrogen was doped at a level of $1.5 \times 10^{19} \mathrm{~cm}^{-3}$ [2]. This steep temperature dependence of $\rho_{\mathrm{C}}$ for contacts in the $\mathrm{n}++$ region cannot be explained by the carbon vacancy induced donor model (Vc model) proposed by Han and his coworkers [3, 4] because heavy doping eclipses the increased donor effect. Figure 3 shows the interface between the Ni-slicide and the epilayer ( $\mathrm{n}++$ region) captured by high-resolution XTEM, when the $\mathrm{Ni}$ (TLM) electrode was annealed at $1000^{\circ} \mathrm{C}$. We can see from this image that the Ni-silicide just contacts the undeformed and ordered $4 \mathrm{H}-\mathrm{SiC}$ crystal. Previously, Han and Lee used X-ray photoelectron spectroscopy (XPS) to observe the changes in the atomic ratio of $\mathrm{Si} / \mathrm{C}$ at the interface for various annealing temperatures. Their results indicated that, after annealing at $950^{\circ} \mathrm{C}$, the ratio abruptly increased up to $\mathrm{Si} / \mathrm{C}>1.2$, implying that $\mathrm{Vc}$ was produced below the contact [4]. An unbalance in the $\mathrm{Si} / \mathrm{C}$ ratio of more than $20 \%$ would naturally destroy the $4 \mathrm{H}$-crystal structure. That would be inconsistent with our result in Fig. 3. We speculate that this inconsistency was caused by a misinterpretation of XPS depth profiling data. Recently, Calcagno [5] and La Via [6] used deep level transient spectroscopy (DLTS) in an effort to detect a high concentration of $\mathrm{Vc}$ under $950^{\circ} \mathrm{C}$-annealed contacts, as predicted by Han and Lee, but a DLTS signal suggesting the presence of such Vc was not observed at all. Thus, it can be concluded that the Vc model is suspect.

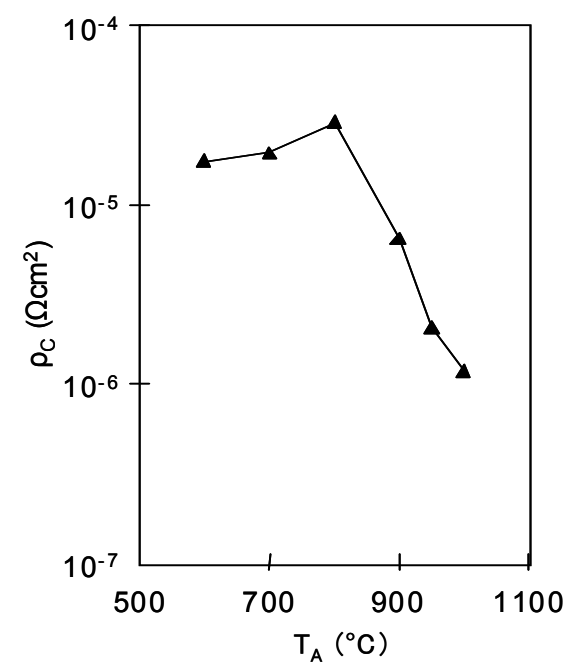

Fig. 2 The average specific contact resistivity, $\rho_{\mathrm{C}}$, of the TLM contacts as a function of RTA temperature, $\mathrm{T}_{\mathrm{A}}$.

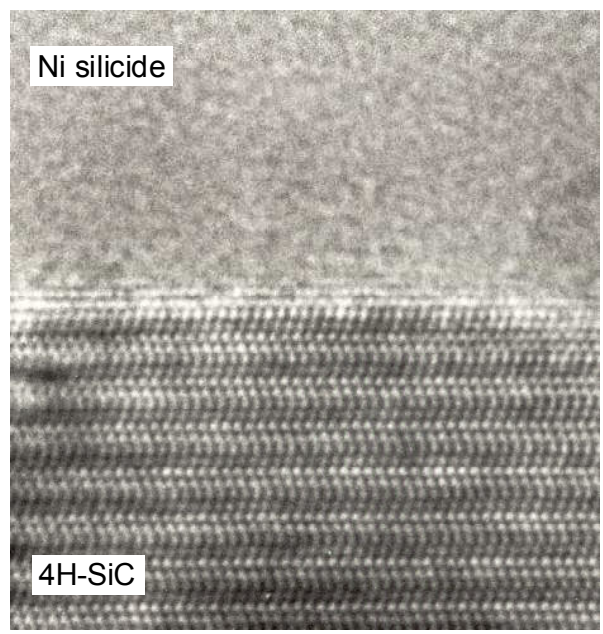

Fig. 3 High resolusion XTEM photograph showing the interface between Ni-silicide and the epilayer ( $\mathrm{n}++$ region). $\mathrm{Ni}$ was annealed at $1000^{\circ} \mathrm{C}$. 


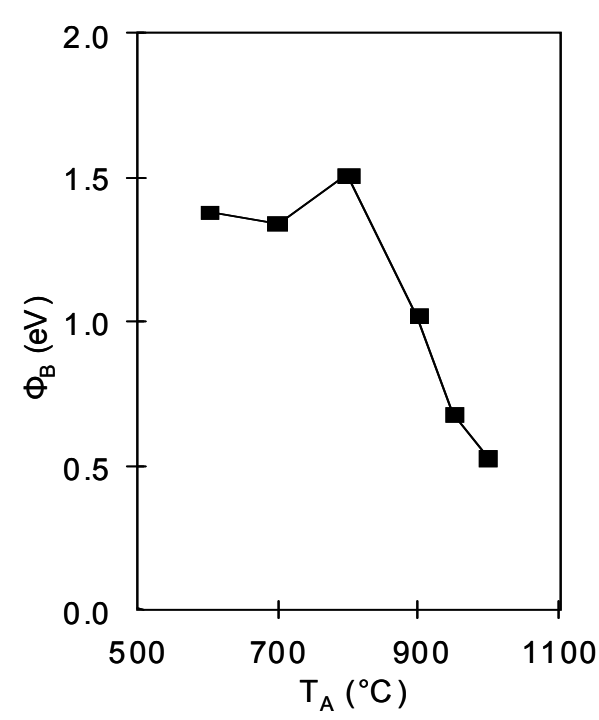

Fig. 4 The Schottky barrier height, $\Phi_{\mathrm{B}}$, of the SBDs as a function of RTA temperature, $\mathrm{T}_{\mathrm{A}}$.

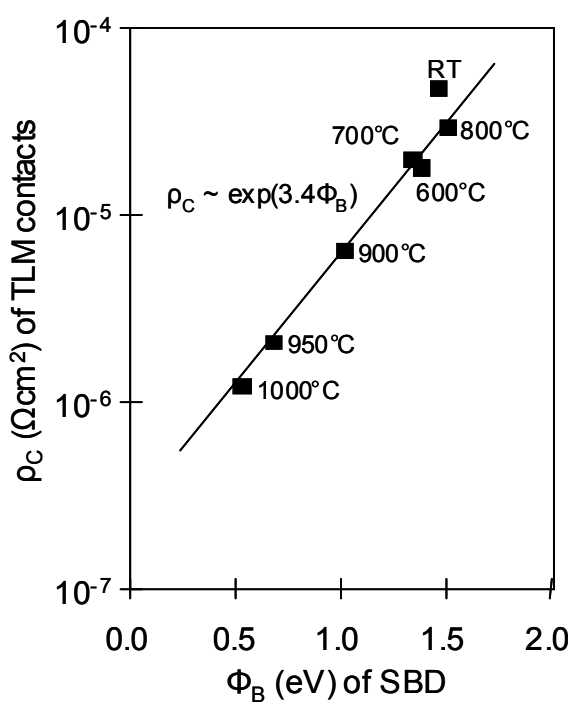

Fig. 5 Correation between specific contact resistivity and Shottky barrier height

Figure 4 displays the $\mathrm{T}_{\mathrm{A}}$ dependence of the Schottky barrier height, $\varphi_{\mathrm{B}}$, of the SBDs where the $\varphi_{\mathrm{B}}$ values were evaluated from their forward IV characteristics. The results indicate that $\varphi_{B}$ also rapidly dropped with increasing $\mathrm{T}_{\mathrm{A}}$ at temperatures above $800^{\circ} \mathrm{C}$. It is interesting that the plotted profile closely resembles that in Fig. 2. Figure 5 plots the correlation between $\log \left(\rho_{C}\right)$ for TLM contacts and $\varphi_{B}$ for the SBDs using $T_{A}$ as the parameter. A significant linear relationship was found between these variables, which strongly suggests that the steep decrease in $\rho_{\mathrm{C}}$ of the TLM contacts shown in Fig. 2 resulted from the marked drop in the $\varphi_{\mathrm{B}}$ of the contacts themselves. This conclusion is based on the fact that the SBDs were probably identical in interface properties to the TLM contacts since they were structurally the same and simultaneously fabricated, the repudiation of the Vc model and the results of the DLTS validations $[5,6]$.

Figure 6 shows (a) an XTEM photograph and (b) an EDS elemental analysis along the yellow line in (a) for the cross section of a blanket contact sample on $4 \mathrm{H}-\mathrm{SiC}$ annealed at $1000^{\circ} \mathrm{C}$ where $\mathrm{Ni}$ was exceptionally $100 \mathrm{~nm}$ in thickness. Note that the EDS signal ratio of $\mathrm{Ni}$ to $\mathrm{Si}$ was adjusted so as to be 2 in the major part of the Ni-silicide electrode, based on the results of the XRD analysis mentioned earlier. It can be seen from his figure that: (1) the Ni-silicide electrode includes three discrete carbon

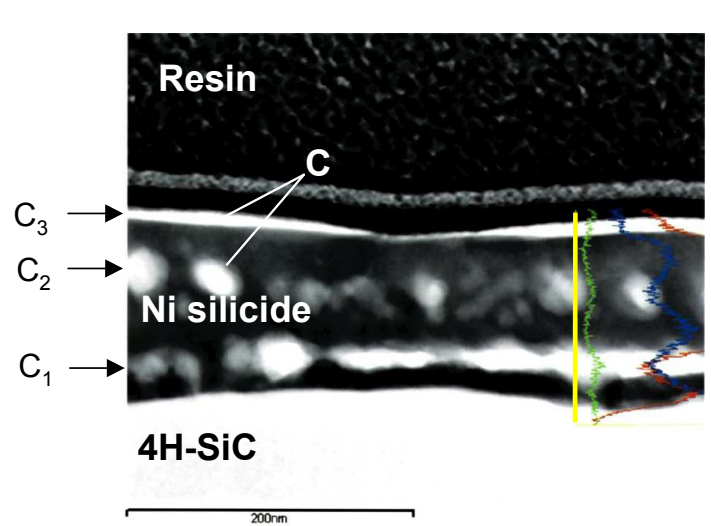

(a)

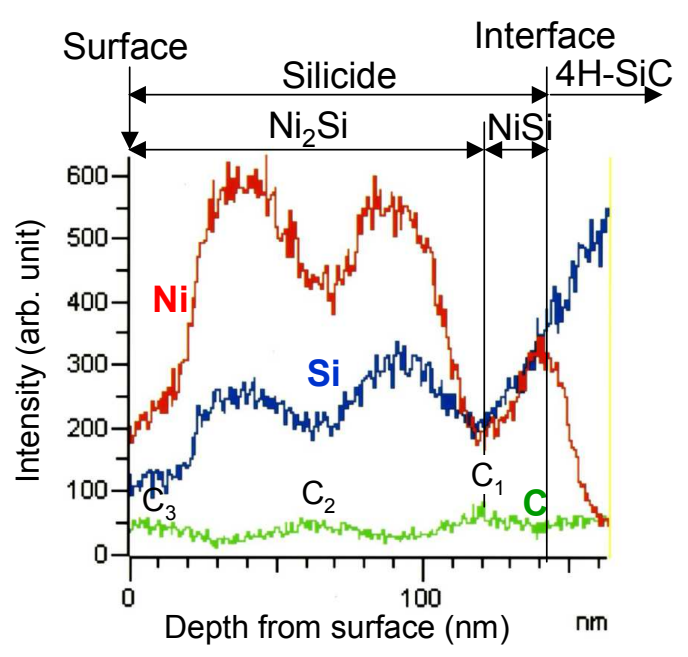

(b)

Fig. 6 XTEM-EDS analysis for a cross section of a blanket Ni contact sample on $4 \mathrm{H}-\mathrm{SiC}$ annealed at $1000^{\circ} \mathrm{C}$ : (a) XTEM photograph and (b) EDS elemental profile along the yellow line in (a). 
bands, $\mathrm{C} 1, \mathrm{C} 2$ and $\mathrm{C} 3$; (2) there is a pure Ni-silicide layer about $20 \mathrm{~nm}$ in thickness between the $\mathrm{C} 1$ band and the $\mathrm{SiC}$ substrate $[2,5]$; (3) this thin silicide layer corresponds in composition to NiSi rather than to $\mathrm{Ni}_{2} \mathrm{Si}$. The formation of NiSi is thermodynamically feasible at higher temperatures $>900^{\circ} \mathrm{C}$ since the Gibbs free energy, $\Delta \mathrm{G}$, is negative in the reaction [7],

$$
\mathrm{Ni}+\mathrm{SiC}-->\mathrm{NiSi}+\mathrm{C}, \Delta \mathrm{G}_{950^{\circ} \mathrm{C}}=-34.4 \mathrm{~kJ} / \mathrm{mol} \text {. }
$$

Actually, Han et al. $[3,4,8]$ and Kuchuk et al. [9] indicated the presence of NiSi right above the C1 band for $950^{\circ} \mathrm{C}$ annealing and at the substrate interface for $1050^{\circ} \mathrm{C}$ annealing, respectively. Probably, the $\mathrm{NiSi} / 4 \mathrm{H}-\mathrm{SiC}$ system might be lower in $\varphi_{\mathrm{B}}$ than the $\mathrm{Ni}_{2} \mathrm{Si} / 4 \mathrm{H}-\mathrm{SiC}$ system. Thus, the following plausible model is proposed which may explain why low contact resistivity is achieved with annealing of $\mathrm{Ni}$ on $\mathrm{SiC}$ at temperatures higher than $950^{\circ} \mathrm{C}$ : when the RTA temperature exceeds $\sim 900^{\circ} \mathrm{C}, \mathrm{NiSi}$ (inducing lower $\varphi_{\mathrm{B}}$ ) starts to form or gather at the $\mathrm{SiC}$ substrate interface; as a result, the contact resistivity steeply declines and finally reaches its minimum when the interface is completely covered with NiSi.

\section{Summary}

Ni-based (TLM) contacts formed in the $\mathrm{n}++$ region exhibited a steep reduction in contact resistivity with annealing at $\mathrm{T}_{\mathrm{A}}>900^{\circ} \mathrm{C}$. The carbon vacancy induced donor model cannot well explain this reduction. A linear relationship was clearly observed between $\log \left(\rho_{C}\right)$ for TLM contacts and $\varphi_{\mathrm{B}}$ for SBDs when plotted using $\mathrm{T}_{\mathrm{A}}$ as a parameter. This fine correlation strongly suggests that the steep reduction in $\rho_{\mathrm{C}}$ of the TLM contacts does not result from an increase in carrier concentration under the contacts but from a decrease in their $\varphi_{\mathrm{B}}$. XTEM-EDS analysis revealed that the substrate surface annealed at $1000^{\circ} \mathrm{C}$ was covered with a very thin Si-rich silicide, most probably, NiSi. It is presumed that the formation of the $\mathrm{NiSi} / \mathrm{SiC}$ system contributes to the significant reduction in contact resistivity observed with contact annealing at temperatures above $900^{\circ} \mathrm{C}$.

\section{Acknowledgments}

This work was supported in part by the "Future Power Electronics Technology (Green IT)" project directed by the New Energy and Industrial Technology Development Organization (NEDO) of Japan.

\section{References}

[1] F. Roccaforte, F. La Via and V. Raineri, Int'1 J. High Speed Electron. Sys., Vol. 15, p. 781 (2005).

[2] S. Tanimoto, H. Okushi and K. Arai, Silicon Carbide -- Recent Major Advances (Eds. W.J. Choyke, H. Matsunami and G. Pensl), Springer Verlag, Berlin-Heiderberg (2004), p. 651.

[3] S.Y. Han, K.H. Kim, J.K. Kim, H.W. Jan, K.H. Lee, N.-K Kim, E.D. Kim and J.-L. Lee, Appl. Phys. Lett., Vol. 79, p. 1816 (2001).

[4] S.Y. Han and J.-L. Lee, J. Electrochem. Soc., Vol. 149, p. G189 (2002).

[5] L. Calcagno, E. Zanetti, F. La Via, F. Roccaforte, V. Raineri, S. Libertino, F. Giannazzo, M, Mauceri and P. Musumeci, Mater. Sci. Forum, Vols. 433-436, p. 721 (2003).

[6] F. La Via, R. Roccaforte, V. Raineri, M. Mauceri, A. Ruggiero, P. Musemeci, L. Calcago, A. Castaldini and A. Cavallini, Microelectron. Engineering, Vol. 70, p. 519 (2003).

[7] C.-S. Lim, K.-B. Shim, D.-W. Shin and K.H. Auh, Korean J. Ceramics, Vol. 2, p. 19 (1996).

[8] S.Y. Han, J.-Y. Shin, B.-T. Lee and J.-L. Lee, J. Vac. Sci. Technol. B, Vol. 20, p. 1496 (2002).

[9] A.V. Kuchuk, V.P. Kladko, A. Piotrowska, R. Ratajczak and R. Jakiela, Mater. Sci. Forum, Vols. 615-617, p. 573 (2009). 